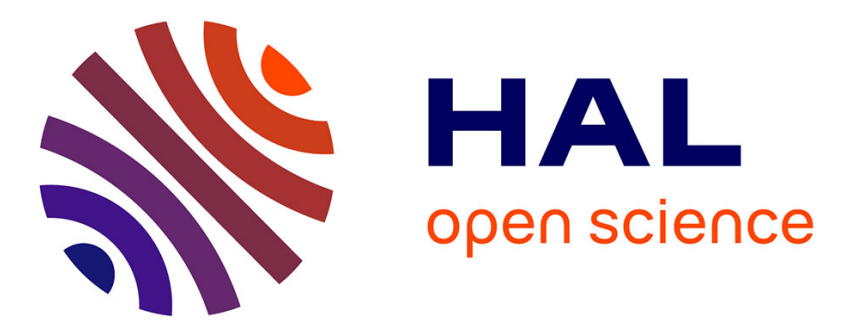

\title{
Effects of pollutants on laccase activities of Marasmius quercophilus, a white-rot fungus isolated from a Mediterranean schlerophyllous litter
}

\author{
Anne Marie Farnet da Silva, G. Gil, Elisée Ferré
}

\section{To cite this version:}

Anne Marie Farnet da Silva, G. Gil, Elisée Ferré. Effects of pollutants on laccase activities of Marasmius quercophilus, a white-rot fungus isolated from a Mediterranean schlerophyllous litter. Chemosphere, 2008, 70 (5), pp.895-900. 10.1016/j.chemosphere.2007.06.086 . hal-02069546

HAL Id: hal-02069546

https://hal.science/hal-02069546

Submitted on 15 Mar 2019

HAL is a multi-disciplinary open access archive for the deposit and dissemination of scientific research documents, whether they are published or not. The documents may come from teaching and research institutions in France or abroad, or from public or private research centers.
L'archive ouverte pluridisciplinaire HAL, est destinée au dépôt et à la diffusion de documents scientifiques de niveau recherche, publiés ou non, émanant des établissements d'enseignement et de recherche français ou étrangers, des laboratoires publics ou privés. 



\title{
Effects of pollutants on laccase activities of Marasmius quercophilus, a white-rot fungus isolated from a Mediterranean schlerophyllous litter
}

\author{
A.M. Farnet ${ }^{\mathrm{a}, *}$, G. Gil ${ }^{\text {b }}$, E. Ferre ${ }^{\text {a }}$ \\ a Equipe Ecologie Microbienne, Service 452, U.M.R. C.N.R.S. 6116, Institut Méditerranéen d'Ecologie et de Paléoécologie, \\ Faculté des Sciences et Techniques de St Jérôme, Université Paul Cézanne, Marseille, France \\ ${ }^{\mathrm{b}}$ Equipe Biocatalyse, U.M.R. C.N.R.S. 6180, Faculté des Sciences et Techniques de St Jérôme, Université Paul Cézanne, Marseille, France
}

\begin{abstract}
Marasmius quercophilus is a white-rot fungus involved in carbon recycling in Mediterranean ecosystems because of its laccase production. Here we described the effect of metal ions and halide salts, on laccase activity in order to point out the action of such environmental pollutants on this enzyme of major importance. Furthermore we tested organic solvent effects on laccase reaction since reaction mixture including solvent can be used in the transformation of xenobiotics. In the case of metal ions, we found that chloride ions were responsible for inhibition while $\mathrm{CuSO}_{4}$ and $\mathrm{MnSO}_{4}$ enhanced laccase activity. When halides were tested, we showed the following degree of inhibition: $\mathrm{F}^{-}>\mathrm{Cl}^{-}>\mathrm{Br}^{-}$. Furthermore we found that $\mathrm{I}^{-}$was oxidized by laccase with $\mathrm{I}_{2}$ as the product of the reaction. With ABTS, $50 \%$ of the laccase activity remains for solvent concentration ranging from $40 \%$ to $60 \%$ depending on the solvent used while with syringaldazine solvent concentration ranged from $50 \%$ to $70 \%$. The organic solvent effects observed were probably a result of enzyme denaturation and of both enhancement of oxidised product solubilisation and of substrate solubilisation (for syringaldazine). These results show that laccase from M. quercophilus is not rapidly inhibited by certain environmental pollutants which sustains its role in carbon turnover under pertubation. However the strong effect of chloride ion on laccase activity should be further investigated with in situ studies since this could drastically influence carbon recycling in litters from Mediterranean littoral locations.
\end{abstract}

Keywords: Halide; Laccase; Metal ions; Organic solvent

\section{Introduction}

Laccases are blue copper phenoloxidases which are mainly produced by white-rot fungi but which are also expressed in bacteria or plants. In natural ecosystems these enzymes oxidize phenolic compounds from lignin while reducing oxygen to water. They raised great interest because of the reaction they catalyse: their action is nonspecific and thus they can oxidize various substrates. Thus these enzymes have been extensively used in biotechnologies for the transformation of aromatic compounds such as dyes, aromatic pollutants or in wastewater treatments

\footnotetext{
${ }^{*}$ Corresponding author. Tel./fax: +33491288190.

E-mail address: a-m.farnet@univ.cezanne.fr (A.M. Farnet).
}

(Farnet et al., 2004; Rodríguez et al., 2004; Jaouani et al., 2005; Rodríguez Couto et al., 2005).

Our studies have focused on laccases from the white-rot fungus Marasmius quercophilus, which is a basidiomycete colonizing Mediterranean ecosystems such as evergreenor cork-oak litters. We have shown that this fungus is involved in carbon recycling (Farnet et al., 2004) in these particular ecosystems submitted to great environmental pressures such as drought and edaphic conditions (little organic matter available, schlerophyllous litters). In these specific conditions, $M$. quercophilus plays an important role in organic matter recycling since it produces laccases which are involved in phenol degradation which is a major limiting factor in carbon recycling because of the structure of these molecules. Thus, studying the effect of environmental pollutants on the activity of such enzymes is of great 
importance in order to assess the resilience potential of Mediterranean ecosystems, already weakened by natural environmental conditions. Here we describe the effect of metal ions, which are common soil pollutants with strong toxic potentials. We wanted to investigate whether such ions may inhibit laccase activity and, thus, have an effect on carbon recycling in forest litter. We have also tested organic solvent and halide salt effects on laccase reaction. The effect of solvents on laccase activity may be of great interest since most of aromatic pollutants can only be dissolved in organic solvents. Thus laccase involvement in xenobiotic transformation has to be monitored using cosolvents and sometime using biphasic reaction mixtures (Bogdanovskaya et al., 2002). Many studies have depicted laccase activity in various experimental conditions, but few have already gathered data about the actions of these various compounds. Thus, in this study we want to explain more precisely the inhibition observed since a weaker activity may have various causes depending on experimental conditions.

\section{Materials and methods}

\subsection{Isolation of the strain}

Strain 19 was isolated from a part of the site of La Gardiole de Rians, Var, France (1 ha) using the rhizomorphic form of the fungus (Farnet et al., 1999). A fungal cap culture was firstly grown on a malt extract agar medium (MEA), $20 \mathrm{~g}^{-1}$ (Bio Mérieux, France) and chloramphenicol, $50 \mathrm{mg} \mathrm{l}^{-1}$ (Sigma). Secondly, the pure mycelial culture obtained was used to inoculate an agar medium (whole wheat flour, $20 \mathrm{~g} \mathrm{l}^{-1}$ ) which favours rhizomorph production. Then one rhizomorph was used to inoculate a MEA plate to obtain a pure dicaryotic culture.

\subsection{Culture conditions and partial purification of laccase}

Pre-cultures were performed in $200 \mathrm{ml}$ Erlenmeyer flasks with $50 \mathrm{ml}$ of MEA (Bio Mérieux, Marcy l'Etoile, France) $20 \mathrm{~g}^{-1}$ and $\mathrm{CuSO}_{4}, 5 \mathrm{~g} \mathrm{l}^{-1}$. They were inoculated with a plug ( $1 \mathrm{~cm}$ diameter) of a fungal culture grown on MEA $\left(20 \mathrm{~g}^{-1}\right)$ and incubated at $25^{\circ} \mathrm{C}$ for 4 days. These pre-cultures were used to inoculate two 3 l-Erlenmeyer-flasks with $400 \mathrm{ml}$ of MEA $20 \mathrm{~g} \mathrm{l}^{-1}$ and $\mathrm{CuSO}_{4}, 5 \mathrm{~g} \mathrm{l}^{-1}$. Cultures were incubated at $25^{\circ} \mathrm{C}$ for 5 days. Enzyme activity was measured by following the oxidation of syringaldazine $[N$, $N^{\prime}$-bis-(3,5-dimethoxy-4-hydroxybenzylidene)hydrazine] to quinone $\left(\varepsilon^{\mathrm{M}}=65000 \mathrm{M}^{-1} \mathrm{~cm}^{-1}\right)$ at $525 \mathrm{~nm}$ in acetate buffer $0.1 \mathrm{M}, \mathrm{pH} 4.0$ on a spectrophotometer Kontron Uvikon 860. One unit (U) of laccase activity is defined as the amount of enzyme that oxidises $1 \mu$ mole of the substrate per minute. The reaction mixture contained $500 \mu \mathrm{l}$ of the medium, $10 \mu \mathrm{l}$ of syringaldazine $(0.6 \%$ in methanol) and $2.5 \mathrm{ml}$ of acetate buffer. Cultures were filtered on a glass microfibre filter GF/D, $2.7 \mu \mathrm{m}$ (Whatman, England). The filtered medium was concentrated using dialysis tubes
(Cellu Sep, VWR, France) rated at $10 \mathrm{MW}(10 \mathrm{kD})$ cutoff. A total volume of $100 \mathrm{ml}$ was obtained. The concentrated filtered medium was loaded on an ion-exchange Mono $Q$ in fast performance liquid chromatography (FPLC) equilibrated with phosphate buffer $0.1 \mathrm{M}$ pH 6.0 (Dédeyan et al., 2000). Laccase was eluted with a step gradient $(0.2 \mathrm{M}, 0.4 \mathrm{M}, 2 \mathrm{M} \mathrm{NaCl})$ for $30 \mathrm{~min}$ at a flow rate of $1 \mathrm{ml} \mathrm{min}{ }^{-1}$. Laccase purity was checked on a PAGE (polyacrylamide gel electrophoresis) carried out according to Laemmli (1970) using 4\% stacking gel and 7.5\% separating gel at $220 \mathrm{~V}$ with the Mini-Protean II electrophoresis cell (Biorad) and protein was stained using the Coomassie Blue standard method.

Effects of organic solvents on laccase activity. Laccase activity was measured in acetate buffer, $0.1 \mathrm{M}, \mathrm{pH} 4$, with syringaldazine or ABTS as substrates at a final concentration of $4.5 \mathrm{mM}$ with $10 \mu \mathrm{l}$ of the purified enzyme in a final volume of $1 \mathrm{ml}$. Organic solvents (methanol, ethanol, acetone, acetonitrile and dioxan) were used at final concentrations of $5 \%, 10 \%, 15 \%, 20 \%, 30 \%, 50 \%, 70 \%$ and $80 \%$ in the reaction mixture. The reaction was followed for two minutes, immediately after adding the solvent into the reaction mixture. A control test was performed without solvent and using syringaldazine or ABTS as substrates as described above. The amount of laccase activity measured was calculated as a percentage of the activity in the control test. Each experiment was repeated twice. Results are expressed as percentage averages with standard deviations for both experiments.

Effect of metal ions and halides on laccase activity. Laccase activity was measured as described above with metal ions solubilised in acetate buffer $0.1 \mathrm{M}, \mathrm{pH} 4$, at different concentrations $(10 \mu \mathrm{M}, 50 \mu \mathrm{M}, 0.25 \mathrm{mM}, 0.5 \mathrm{mM}, 1 \mathrm{mM}$, $2.5 \mathrm{mM}, 5 \mathrm{mM}, 10 \mathrm{mM}, 15 \mathrm{mM}$ and $20 \mathrm{mM}$ ) depending on the metal ion tested (Robles et al., 2002; Lorenzo et al., 2006). Laccase activity was measured immediately after the addition of the metal ion tested and a control without metal ion was also performed. The amount of laccase activity measured was calculated as a percentage of the activity in the control test. The ions tested were: $\mathrm{Cu}^{2+}$ as $\mathrm{CuCl}_{2}, \mathrm{CuSO}_{4}, \mathrm{Mn}^{2+}$ as $\mathrm{MnCl}_{2}, \mathrm{MnSO} 4, \mathrm{Hg}^{2+}$ as $\mathrm{HgCl}_{2}$, $\mathrm{Ca}^{2+}$ as $\mathrm{CaCl}_{2}$ and $\mathrm{Na}^{2+}$ as $\mathrm{NaCl}$. To test the abiotic effect of $\mathrm{Fe}^{2+}$ on the quinone of syringaldazine, a control test was realized by adding $30 \mu \mathrm{l}$ of a solution of $\mathrm{Fe} \mathrm{SO}_{4}(20 \mathrm{mM}$ final concentration) after a 2 min reaction between laccase and syringaldazine and a spectral scan from $200 \mathrm{~nm}$ to $700 \mathrm{~nm}$ was performed. To test the abiotic oxidation of $\mathrm{Fe}^{3+}$ on syringaldazine, $\mathrm{Fe}\left(\mathrm{NO}_{3}\right)_{3}$ and $\mathrm{Fe}_{2}\left(\mathrm{SO}_{4}\right)_{3}$ at $20 \mathrm{mM}$ were added to syringaldazine, $4.5 \mathrm{mM}$ without laccase and a spectral scan from $200 \mathrm{~nm}$ to $700 \mathrm{~nm}$ was realized.

The effect of halide ions on laccase activity was measured as described above using the following concentrations: $5 \mathrm{mM}, 10 \mathrm{mM}, 15 \mathrm{mM}, 20 \mathrm{mM}$ and $25 \mathrm{mM}$. A control test without halide ions was also performed. Furthermore, $\mathrm{I}^{-}$oxidation was measured under the same experimental conditions but with $\mathrm{NaI}$ concentrations of 
$100 \mathrm{mM}, 200 \mathrm{mM}$ and $400 \mathrm{mM}$. Each experiment was repeated twice. Results are expressed as percentage average with standard deviations for both experiments.

\section{Results and discussion}

Ion exchange chromatography allowed us to purify the constitutive isoform of laccase from strain 19 (Fig. 1) produced under these culture conditions: malt extract, $20 \mathrm{~g}^{-1}$, $\mathrm{CuSO}_{4}, 5 \mathrm{mg} \mathrm{l}^{-1}$ (Farnet et al., 1999). We obtained a purification factor of 324 (calculated using specific activities) and a total yield of $81 \%$ (using total activities). Thus, this one step purification allowed us to reach a satisfactory yield of purification in order to assess the effects of the pollutants selected, on this isoform activity. As described previously, the $M$. quercophilus strains isolated from the site of La Gardiole have similar electrophoretic patterns of laccase isoenzymes (Farnet et al., 1999). Thus, this study sustains our previous observations: the constitutive isoform found here has a similar molecular weight of $60 \mathrm{kDa}$ (Fig. 1) than that observed with strain 17 (Farnet et al., 2000) which was collected at the same time in La Gardiole de Rians (Var, France). Intraspecific isoenzyme homogeneity has been observed for many fungal species such as Agaricus bisporus (Kerrigan and Ross, 1998).

In this study, we tested the effect of various solvents on this laccase isoform activity. The inhibiting concentration where $50 \%$ of laccase activity remains (IC 50 ) was $75 \%$ with ethanol, $65 \%$ with acetone, $60 \%$ with methanol, $55 \%$ with acetonitrile, $45 \%$ with dioxane when syringaldazine was used as a substrate. IC 50 was $60 \%$ with ethanol, $50 \%$ with acetonitrile, $40 \%$ with methanol and acetone and 30\% with dioxane when ABTS was used as a substrate. When laccase activity was measured with syringaldazine as a substrate, an increase in activity with ethanol, methanol, acetonitrile and acetone was observed in a range from 0 to $40 \%$ of solvent (Fig. 2). When solvent were added at $50 \%$ and more, laccase activity decreased except for ethanol (the decrease started at $60 \%$ of ethanol). With dioxan, laccase activity increased when $5 \%$ of solvent were used, was stable in a range from $10 \%$ to $30 \%$ and decreased when higher concen-

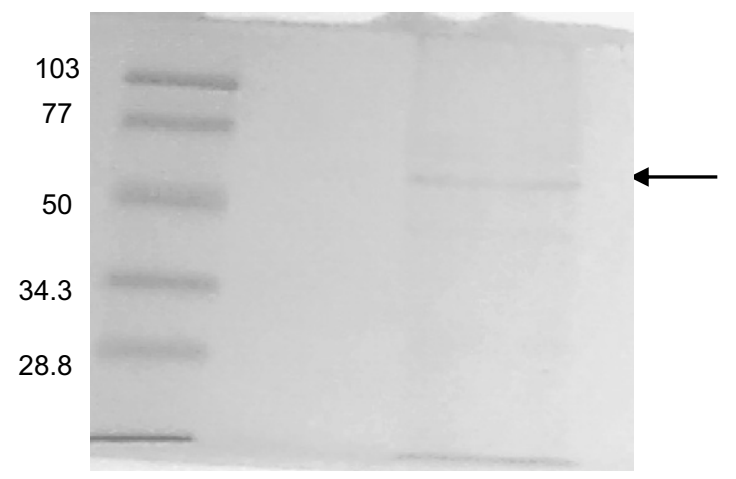

Fig. 1. Electrophoretic profile of the purified constitutive laccase from Marasmius quercophilus strain 19 on SDS-PAGE. Molecular weight markers on the left line $(\mathrm{kDa})$.
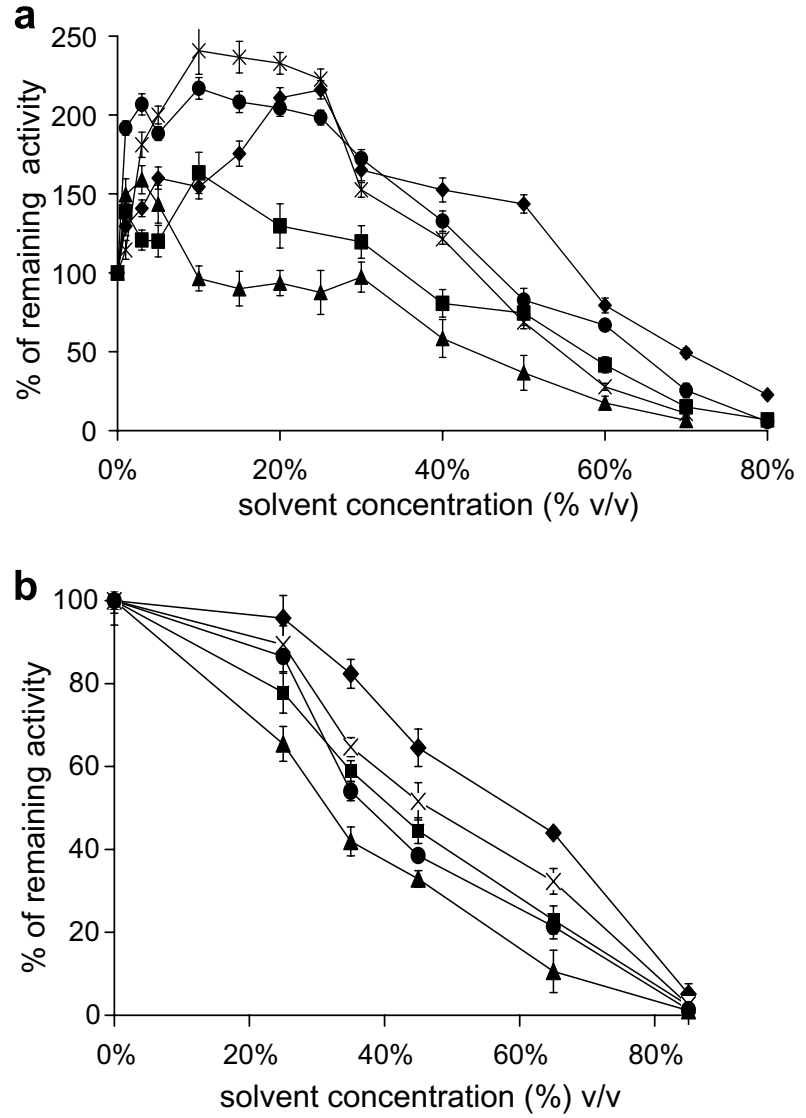

Fig. 2. Percentage of remaining laccase activity using syringaldazine (a) or ABTS (b) as a substrate with solvent concentrations ranging from $0 \%$ to $80 \%$. Solvents used were: methanol (⿴) ethanol $(\bullet)$, acetone $(\bullet)$, acetonitrile $(\times)$, dioxane $(\boldsymbol{\Delta})$.

trations of this solvent were used. Thus, ethanol was found to be the weakest inhibiting solvent (50\% of laccase activity remained with $70 \%$ of ethanol) while dioxan exhibited the strongest effect. When laccase activity was measured with ABTS, a greater inhibition was observed since the decrease in enzyme activity started at $25 \%$ of solvent concentration whatever the solvent used (Fig. 2). For this concentration, with syringaldazine as a substrate, the percentage of activity ranged from 87 to $220 \%$ and with ABTS, from 65 to $95 \%$.

Robles et al. (2002) have shown a greater decrease in laccase activity with methanol, ethanol, acetonitrile and acetone at $25 \%$, respectively $63.6 \%, 73 \%, 16 \%$ and $29.5 \%$ of remaining activity as well as in the study of Cambria et al. (2000) who have found an inhibition of 50\% of laccase activity when methanol was used at $50 \%$ (in our study, with $50 \%$ of methanol, about $100 \%$ of laccase activity remains when syringaldazine was used as the substrate). This result may be explained by the fact that these laccases are produced by other fungal species and thus, M. quercophilus laccase seems to exhibit a greater stability when used with solvents. This result suggests the particular resistance of this laccase towards organic solvents. Furthermore, certain organic solvents improve the solubilisation of 
substrates such as syringaldazine which are commonly solubilized in methanol. In the case of ABTS, which is solubilized in water, laccase activity did not increase (laccase activity was not higher than that of the control test) and the effect of the solvent used on the enzyme itself may be observed. Thus, when the substrate used is more apolar, the effect of solvent on substrate solubilization is greater than that on the enzyme at least for solvent concentration below 30\%. This result can be correlated with the fact that the quinone of syringaldazine produced by laccase was also more stable when solvents were used. Indeed, in the control test without solvent, the absorbance at $525 \mathrm{~nm}$ quickly decreased after a 2 min - reaction suggesting that the quinone produced may have polymerized (Fig. 3). When the reaction was performed with $20 \%$ of methanol, the absorbance at $525 \mathrm{~nm}$ did not decrease through time but remained constant (absorbance at $525 \mathrm{~nm}$ was monitored for $10 \mathrm{~min}$ ). Polymerization seems to be stopped since the quinone is solubilized in methanol. The instability of laccase oxidation-products in aqueous medium have been shown in previous studies (Farnet et al., 2004; Mustafa et al., 2005). Thus, the use of hydro-organic mixtures in enzymatic reactions involving apolar molecules is of great interest since the solubilization of substrate is improved and the product of the reaction can be found in the organic phase. In further studies, apolar solvents should be used in a biphasic reaction mixture in order to check whether this methodology allows a final-product extraction in the organic phase while the reaction occurs.

We have also shown that dioxan and acetone, which are the most apolar solvents used in this study, were the strongest inhibiting solvents. With acetone, the inhibition was easily observable with ABTS (solubilized in water) while with syringaldazine, acetone improved quinone solubilization which affected enzyme inhibition observation. This result is in agreement with the work of RodakiewiczNowak et al. (2000), who have described the effects of acetonitrile, acetone and dimethyl sulfoxide (DMSO) on laccase activity and found that hydrophobicity was the major factor involved in the enzyme inhibition because of enzyme denaturation. They have also found that laccase

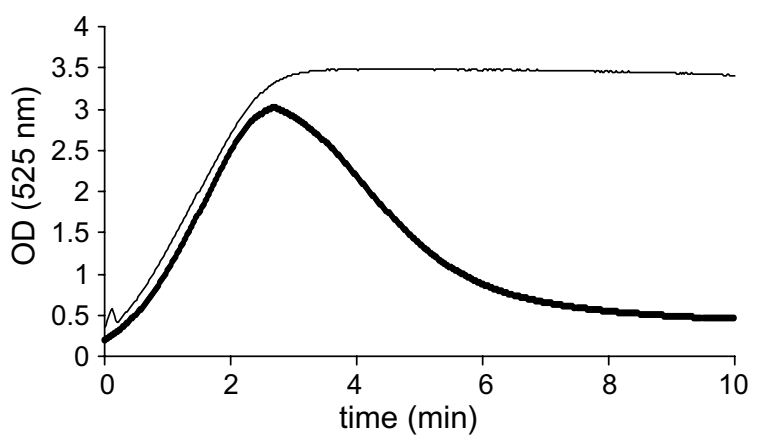

Fig. 3. Stability of syringaldazine quinone, syringaldazine oxidation with laccase in acetate buffer $0.1 \mathrm{M}, \mathrm{pH} 4.0$ with (-) or without $(-) 20 \%$ of methanol is followed at $525 \mathrm{~nm}$ for $10 \mathrm{~min}$. inhibition with organic solvents strongly depends on the substrate used to detect laccase activity since the inhibition can be competitive or mixed. In the case of a competitive inhibition, the effects observed may vary depending on the nature of the substrate and, thus, on the degree of competition with the organic solvent. Another mechanism which should be taken into account is that laccases can aggregate in solution and be present as a non-active resting form depending on various parameters such as protein concentrations, temperature and oxygenation (Schleev et al., 2006). Thus the concentration of native fully-active laccase is not similar to the total concentration of the enzyme. Solvents may also have an effect on enzyme aggregation and therefore may influence the native fully-active enzyme concentration in the solution. Thus, in order to assess laccase inhibition with organic solvents, the combination of different mechanisms must be taken into account: the inhibition observed may vary depending on the substrate used, the oxidation product solubility in solvent may lead to an apparent absence of inhibition, protein may be denaturated with different solvent concentrations depending on the enzyme studied. Pre-incubation of laccase in solvents should be performed to assess the effect of enzyme denaturation on its activity.

With metal ions, we have shown variable responses of laccase activity depending on the ions and the substrate used. IC 50 was of $13 \mathrm{mM}$ with $\mathrm{HgCl}_{2}$, of $1 \mathrm{mM}$ with $\mathrm{MnCl}_{2}, \mathrm{CaCl}_{2}, \mathrm{NaCl}$ and of $0.5 \mathrm{mM}$ with $\mathrm{CuCl}_{2}$ when syringaldazine was used as a substrate and of $25 \mathrm{mM}$ with $\mathrm{MnCl}_{2}, \mathrm{CuCl}_{2}, \mathrm{NaCl}$ and of $17 \mathrm{mM} \mathrm{CaCl}_{2}$ when ABTS was used as a substrate. With syringaldazine, $\mathrm{Fe}\left(\mathrm{NO}_{3}\right)_{3}$ and $\mathrm{Fe}_{2}\left(\mathrm{SO}_{4}\right)_{3}$ induced an increase in quinone production while $\mathrm{FeSO}_{4}$ led to a quick decrease in absorption. The control test with syringaldazine and $\mathrm{Fe}\left(\mathrm{NO}_{3}\right)_{3}$ or $\mathrm{Fe}_{2}\left(\mathrm{SO}_{4}\right)_{3}$ without the enzyme, suggests that an abiotic oxidation of the substrate occurs since quinone production was observed (data not shown). Furthermore, when $\mathrm{FeSO}_{4}$ was added one or two minutes after syringaldazine oxidation started (Fig. 4), the spectral scan showed than the quinone of syringaldazine was transformed but did not lead to the initial compound (a new peak at $300 \mathrm{~nm}$ was observed).

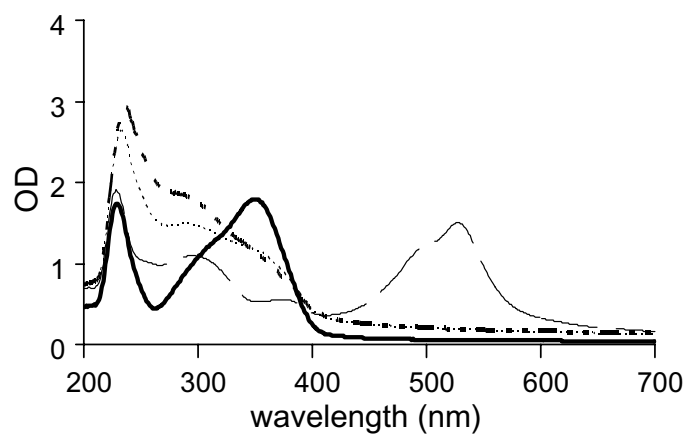

Fig. 4. Transformation of syringaldazine quinone with $\mathrm{FeSO}_{4}$, (-) syringaldazine, (--) syringaldazine and laccase, (---) syringaldazine and laccase, $1 \mathrm{~min}$ after adding $\mathrm{FeSO}_{4}$, (--) syringaldazine and laccase, 2 min after adding $\mathrm{FeSO}_{4}$. 
When sulphate salts such as $\mathrm{CuSO}_{4}$ and $\mathrm{MnSO}_{4}$ were tested, an increase in laccase activity occurred (Fig. 5). Laccase production enhancement when $\mathrm{CuSO}_{4}$ was added in fungal culture has been extensively described (Farnet et al., 1999; Baldrian and Gabriel, 2002; Lorenzo et al., 2006) which may be explained by gene-expression induction. However when added to a purified enzyme, $\mathrm{CuSO}_{4}$ provoked various effects depending on the laccase tested: Lorenzo et al. (2005) have found a great laccase inhibition (about $40 \%$ of inhibition with $20 \mathrm{mM}$ of $\mathrm{CuSO}_{4}$ ) with a laccase from Trametes versicolor while Baldrian and Gabriel (2002) have shown that laccase activity increases and remains stable with a $\mathrm{CuSO}_{4}$ concentration of $50 \mathrm{mM}$. Munoz et al. (1997) have demonstrated that semiquinone produced by laccases can be transformed to quinone via autooxidation involving oxygen. The superoxide anion produced in this reaction is then reduced to hydrogen peroxide. In our study, $\mathrm{Cu}^{2+}$ or $\mathrm{Mn}^{2+}$ may favour the role of oxygen and may be reduced to $\mathrm{Cu}^{+}$or $\mathrm{Mn}^{+}$leading to an apparent increase in laccase activity. This result points out that the laccase isoform studied remains active in the presence of certain toxic pollutants and that this activity can even be enhanced by certain ions. Thus, this enzymatic system seems to be strongly involved in ecosystem resilience since carbon recycling linked to phenol degradation would be weakly affected under these stress conditions.

We also tested the effects of halide salts on laccase activity and we observed the following inhibition order, $\mathrm{F}^{-}, \mathrm{I}^{-}$, $\mathrm{Cl}^{-}, \mathrm{Br}^{-}$with $\mathrm{F}^{-}$as the strongest inhibitor (Fig. 6). IC50 was of $20 \mathrm{mM}$ with $\mathrm{NaBr}, 7.5 \mathrm{mM}$ with $\mathrm{NaCl}, 3.3 \mathrm{mM}$ with $\mathrm{NaI}$ and $2.7 \mathrm{mM}$ with $\mathrm{NaF}$. This result is consistent with previous studies on laccases from different fungi (Jung et al., 2002; Kim and Nicell, 2006). Inhibition mechanism of laccases by halide ions has been described by Naki and Varfolomeev (1981): chloride and bromide ions act as competitive inhibitors with the electron donor while $\mathrm{F}^{-}$acts as a non-competitive inhibitor. Furthermore, the degree of inhibition of laccases by halides seems to be linked to the availability of copper atoms (type 2 and type

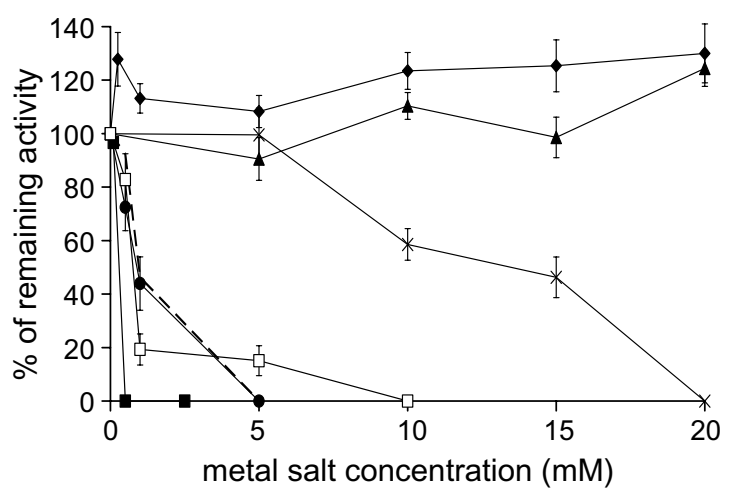

Fig. 5. Percentage of remaining laccase activity using syringaldazine as a substrate with metal salt concentration ranging from 0 to $20 \mathrm{mM}$ depending on the metal salt used : $\mathrm{CuCl}_{2}(\boldsymbol{\square}), \mathrm{CuSO} 4(\bullet), \mathrm{MnCl}_{2}(--)$, MnSO4 (ム) $\mathrm{HgCl}_{2}(\times), \mathrm{CaCl}_{2}(\bullet), \mathrm{NaCl}(\square)$.

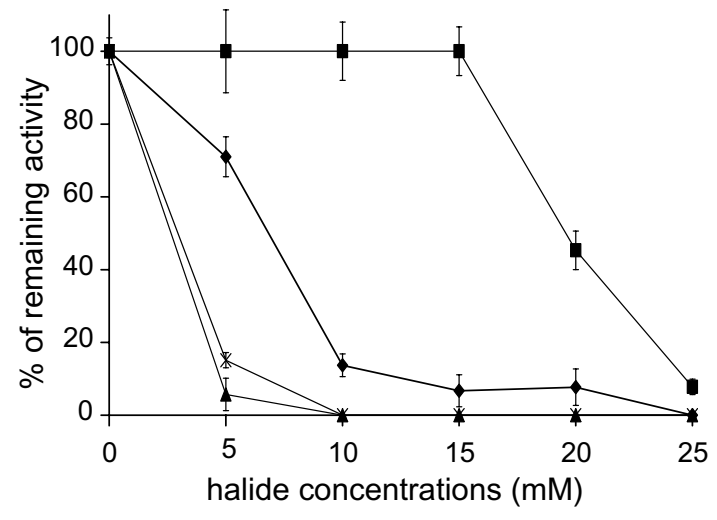

Fig. 6. Percentage of laccase remaining activity using syringaldazine as a substrate with different halide concentrations: $\mathrm{NaBr}(\boldsymbol{\square}), \mathrm{NaCl}(\bullet), \mathrm{NaI}$ $(\times), \operatorname{NaF}(\mathbf{\Lambda})$.

3 ) in the active site (Abadulla et al., 2000). In the case of $\mathrm{NaI}$, we showed that laccase was able to oxidize $\mathrm{I}^{-}$to $\mathrm{I}_{2}$ (Fig. 7) since a strong yellow coloration appeared (absorption at $350 \mathrm{~nm}$ ). Concentrations ranging from $0.1 \mathrm{M}$ to $0.4 \mathrm{M}$ were used in order to favour $\mathrm{I}_{2}$ production monitoring at $350 \mathrm{~nm}$. Thus the inhibition observed when NaI was added to laccase and syringaldazine seems to be due to the use of $\mathrm{I}^{-}$as a substrate. Laccase inhibition by chloride salts was also stated in the experiment involving metal salts. $\mathrm{CuCl}_{2}, \mathrm{CaCl}_{2}, \mathrm{MnCl}_{2}, \mathrm{NaCl}$ and $\mathrm{HgCl}_{2}$ indeed showed a strong inhibition towards laccase activity (Figs. 5 and 8). From an ecological point of view, laccase inhibition with $\mathrm{NaCl}$ is noteworthy since this would mean that carbon recycling may be altered under particular environmental conditions. For instance, in Mediterranean littoral areas where saline concentrations in litters can reach higher levels, carbon turn-over may be less effective. Further studies should investigate whether laccase activities decrease in such ecosystems or whether microbial adaptation may have led to laccase isoforms which are less inhibited by chloride salts.

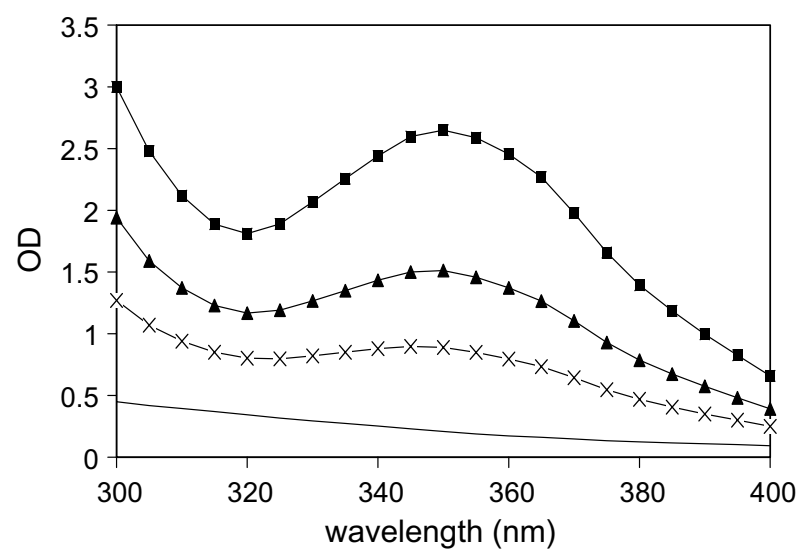

Fig. 7. Absorption variations during $\mathrm{I}^{-}$oxidation to $\mathrm{I}_{2}$ with the laccase of Marasmius quercophilus. NaI concentrations used were: (-) $0 \mathrm{M},(-\times-)$, $0.1 \mathrm{M},(-\mathbf{\Delta}-), 0.2 \mathrm{M},(-\mathbf{-}) 0.4 \mathrm{M}$. 


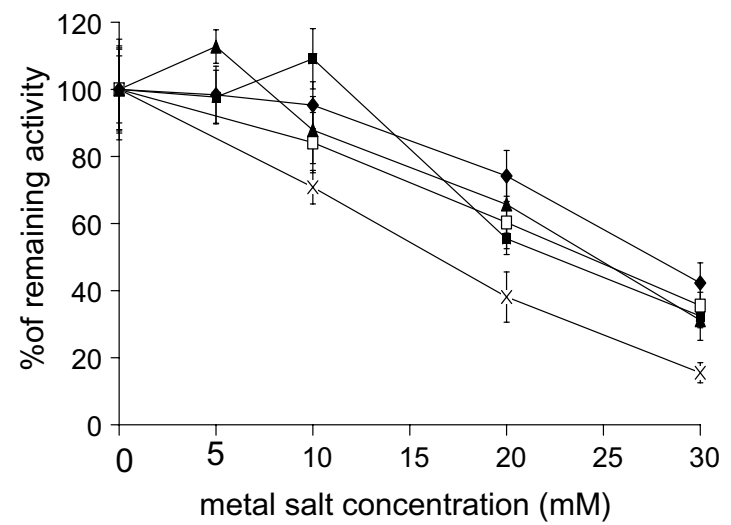

Fig. 8. Percentage of remaining laccase activity using ABTS as a substrate with metal salt concentration ranging from 0 to $20 \mathrm{mM}$ depending on the metal salt used: $\mathrm{CuCl}_{2}(\mathbf{\square}), \mathrm{MnCl}_{2}(\square), \mathrm{HgCl}_{2}(\diamond), \mathrm{CaCl}_{2}(\times), \mathrm{NaCl}(\mathbf{\Delta})$

Mediterranean ecosystems are submitted to anthropic and natural pressures. This work contributes to a better understanding of how a laccase isozyme produced in such fragile ecosystems may be affected by environmental pollutants. Overall, laccase activity was weakly affected by the solvents tested (most of the activity remains for a concentration of $30 \%$ whatever the solvent used). Interestingly we also found that the laccase isoform studied here was not drastically affected by the metal ions tested compared to other studies. Moreover, certain ions, such as $\mathrm{Cu}^{2+}$ or $\mathrm{Mn}^{2+}$, enhanced laccase activity. Actually, chloride ions were the most inhibiting ions, which may have a significant importance in littoral ecosystems. Further studies should investigate whether this enzymatic system may also be involved in environmental detoxification by oxidizing aromatic pollutants. We have already tested laccase activity towards chlorophenols (Farnet et al., 2004) and we should also analyse laccase oxidizing potential with other widespread aromatic pollutants such as polycyclic aromatic hydrocarbons.

\section{References}

Abadulla, E., Tzanov, T., Costa, S., Robra, K.-H., Cavaco-Paulo, A., Gübitz, G., 2000. Decolorization and detoxification of textile dyes with a laccase from Trametes hirsuta. Appl. Environ. Microb. 66, $3357-$ 3362

Baldrian, P., Gabriel, J., 2002. Copper and cadmium increase laccase activity in Pleurotus ostreatus. FEMS Microbiol. Lett. 206, 69-74.

Bogdanovskaya, V.A., Tarracevich, M.R., Kuznetsova, L.N., Reznik, M.F., Kasatkin, E.V., 2002. Peculiarities of direct bioelectrocatalysis by laccase in aqueous-nonaqueaous mixtures. Biosens. Bioelectron. 17, 945-951.

Cambria, M.T., Cambria, A., Ragusa, S., Rizzarelli, E., 2000. Production, purification, and properties of an extracellular laccase from Rigidoporus lignosus. Prot. Exp. Purif. 18, 141-147.
Dédeyan, B., Klonowska, A., Tagger, S., Tron, T., Iacazio, G., Gil, G., Le Petit, J., 2000. Biochemical and molecular characterization of a laccase from Marasmius quercophilus. Appl. Environ. Microb. 66, 925-929.

Farnet, A.M., Tagger, S., Le Petit, J., 1999. Effects of copper and aromatic inducers on the laccases of the white-rot fungus Marasmius quercophilus, C.R.A.S.. Life Sci. 322, 499-503.

Farnet, A.M., Criquet, S., Tagger, S., Gil, G., Ferré, E., 2000. Purification, partial characterization and reactivity with aromatic compounds of two laccases from Marasmius quercophilus strain 17. Can. J. Microbiol. 46, 189-194.

Farnet, A.M., Criquet, S., Cigna, M., Gil, G., Ferré, E., 2004. Purification of a laccase from Marasmius quercophilus induced with ferulic acid : reactivity towards natural and xenobiotic aromatic compounds. Enzymes Microb. Biotechnol. 34, 549-554.

Jaouani, A., Guillén, F., Penninckx, M.J., Martínez, A.T., Martínez, M.J., 2005. Role of Pycnoporus coccineus laccase in the degradation of aromatic compounds in olive oil mill wastewater. Enzymes Microb. Technol. 36, 478-486.

Jung, H., Xu, F., Li, K., 2002. Purification and characterisation of laccase from wood-degrading fungus Trichophyton rubrun LKY-7. Enzymes Microb. Technol. 30, 161-168.

Kerrigan, R.W., Ross, I.K., 1998. Extracellular laccases: biochemical markers for Agaricus systematics. Mycologia 81, 689-695.

Kim, Y.I., Nicell, J.A., 2006. Impact of reaction conditions on the laccasecatalysed conversion of bisphenol A. Bioresource Technol. 97, 14311442.

Laemmli, U.K., 1970. Cleavage of structural proteins during the assembly of the head of bacteriophage T4. Nature 227, 680-685.

Lorenzo, M., Moldes, D., Rodriguez Couto, S., Sanroman, M.A., 2005. Inhibition of laccase activity from Trametes versicolor by heavy metals and organic compounds. Chemosphere 60, 1124-1128

Lorenzo, M., Moldes, D., Sanroman, M.A., 2006. Effect of heavy metals on the production of several laccase isoenzymes by Trametes versicolor and on their ability to decoulorise dyes. Chemosphere 63, 912-917.

Munoz, C., Guillen, A.T., Martinez, A.T., Martinez, M.J., 1997. Laccase isoenzymes of Pleurotus eryngii: characterization, catalytic properties and participation in activation of molecular oxygen and $\mathrm{Mn}^{2+}$ oxidation. Appl. Environ. Microb. 63, 2166-2174.

Mustafa, R., Muniglia, L., Rovel, B., Girardin, M., 2005. Phenolic colorants obtained by enzymatic synthesis using a fungal laccase in a hydro-organic biphasic system. Food Res. Int. 38, 995-1000.

Naki, A., Varfolomeev, S.D., 1981. Inhibition mechanism of Polyporus versicolor laccase by halide ions. Biochemistry 46, 1694-1702.

Robles, A., Lucas, R., Martínez-Cañamero, M., Ben Omar, N., Pérez, R., Gálvez, A., 2002. Characterisation of laccase activity produced by the hyphomycete Chalara (syn. Thielaviopsis) paradoxa $\mathrm{CH} 32$. Enzymes Microb. Technol. 31, 516-522.

Rodakiewicz-Nowak, J., Kasture, S.M., Dudek, B., Haber, J., 2000. Effect of various water-miscible solvents on enzymatic activity of fungal laccases. J. Mol. Cat. B: Enzymatic 11, 1-11.

Rodríguez Couto, S., Sanromán, M.A., Gübitz, G.M., 2005. Influence of redox mediators and metal ions on synthetic acid dye decolourization by crude laccase from Trametes hirsuta. Chemosphere 58, 417-422.

Rodríguez, E., Nuero, O., Guillen, F., Martinez, A.T., Martinez, M.J., 2004. Degradation of phenolic and non-phenolic aromatic pollutants by four Pleurotus species: the role of laccase and versatile peroxidase. Soil Biol. Biochem. 36, 909-916.

Schleev, S., Reimann, C.T., Serezhenkov, V., Burbaev, D., Yaropolov, A.I., Gorton, L., Ruzgas, T., 2006. Autoreduction and aggregation of fungal laccase in solution phase: possible correlation with a resting form of laccase. Biochimie 88, 1275-1285. 